\title{
Gender Differences in the Behavioral Symptom Severity of Prader-Willi Syndrome
}

\author{
Masao Gito, ${ }^{1,2,3}$ Hiroshi Ihara, ${ }^{1}$ Hiroyuki Ogata, ${ }^{1,3}$ \\ Masayuki Sayama, ${ }^{1}$ Nobuyuki Murakami, ${ }^{4}$ Toshiro Nagai, ${ }^{5}$ \\ Tadayuki Ayabe, ${ }^{4}$ Yuji Oto, ${ }^{4}$ and Kazutaka Shimoda ${ }^{3}$ \\ ${ }^{1}$ Department of Psychiatry, Dokkyo Medical University Koshigaya Hospital, 2-1-50 Minami-Koshigaya, Koshigaya, \\ Saitama 343-8555, Japan \\ ${ }^{2}$ Ikezawa Hospital, 551 Shimo-Shingo, Hanyu, Saitama 348-0046, Japan \\ ${ }^{3}$ Department of Psychiatry, Dokkyo Medical University School of Medicine, 880 Kita-Kobayashi, Mibu-Machi, \\ Shimotuka-Gun, Tochigi 321-0293, Japan \\ ${ }^{4}$ Department of Pediatrics, Dokkyo Medical University Koshigaya Hospital, 2-1-50 Minami-Koshigaya, Koshigaya, \\ Saitama 343-8555, Japan \\ ${ }^{5}$ Nakagawanosato Ryoiku Center, 222 Shimo-Akaiwa, Matsubushi-Machi, Kita-Katsushika-Gun, Saitama 343-0116, Japan
}

Correspondence should be addressed to Hiroshi Ihara; cotoncb@dokkyomed.ac.jp

Received 30 July 2015; Accepted 20 October 2015

Academic Editor: Hrayr Attarian

Copyright (C) 2015 Masao Gito et al. This is an open access article distributed under the Creative Commons Attribution License, which permits unrestricted use, distribution, and reproduction in any medium, provided the original work is properly cited.

Objectives. This study measured gender differences in Prader-Willi syndrome (PWS) in regard to the severity of behavioral symptoms. Methods. The Food Related Problem Questionnaire (FRPQ), the Aberrant Behavior Checklist Japanese Version, the Childhood Routines Inventory, the Pervasive Developmental Disorders Autism Society Japan Rating Scale, and Japanese ADHDRS were administered to PWS patients ( 45 males aged 6 to 58 and 37 females aged 6 to 45). To examine the effects that gender and genotype have on the severity of each symptom, two-way ANOVAs were conducted. Results. Significant interactions were found only in regard to FRPQ scores, such as FRPQ total score $(F(1,78)=8.43, p<0.01)$. The FRPQ of male deletion (DEL) individuals was higher than that of female DEL and male mUPD. The FRPQ of male maternal uniparental disomy (mUPD) was lower than that of female mUPD. Conclusions. In terms of problem behaviors, routines, autistic behaviors, and hyperactivity, no significant differences were found. Food-related behaviors in DEL were more severe in males, although those in mUPD were less severe in males.

\section{Introduction}

Prader-Willi syndrome (PWS) is a genetic disorder caused by a loss of expression of the paternally derived genes on chromosome 15q11-13. The causes of this disruption include paternal deletion (DEL) of 15q11-13 and maternal uniparental disomy 15 (mUPD, when both copies of chromosome 15 are maternally inherited) [1]. As a neurodevelopmental disorder, PWS is associated with neonatal hypotonia, hypogonadism, hyperphagia, progressive obesity, and mild to moderate mental retardation [2]. The physical manifestations of PWS include short stature, small hands and feet, hypopigmentation, and craniofacial anomalies. Based on epidemiological surveys, the birth rate is estimated at around 1 in 25,000 [3].

The behavioral manifestations of this syndrome include hyperphagia $[4,5]$, temper tantrums [6], obsessivecompulsive behaviors $[7,8]$, repetitive and ritualistic behavior [9], self-injurious behavior [10,11], autistic behaviors [12, 13], hyperactive/impulsive behaviors [14, 15], and psychiatric disorders [16]. Due to lack of specific drugs in controlling PWS-related behaviors, pharmacological treatment should 
only be used with caution and in combination with behavioral management and psychiatric support [17].

In terms of population prevalence for people with PraderWilli syndrome, the gender ratio is close to $1: 1[1,18-20]$, including non-Western countries [21]. So far, however, there has been little research into gender differences in individuals with PWS in relation to behavioral symptom severity. One piece of data was presented by Dykens [22], who found that females are more inclined to pick their skin than males. Such gender difference in terms of skin picking was also found in individuals with nonspecific mental retardation [23]. When food-related behaviors were analyzed by both gender and genotype, female mUPD patients were found to be less severely affected than female DEL patients in terms of length of gavage feeding and a later onset of hyperphagia. This difference between MUPD and DEL was not found in male patients [24].

Aside from Prader-Willi syndrome, certain mental disorders show marked gender differences in the diagnosis rates. For example, unipolar depression is twice as common in women. In contrast, the prevalence of alcohol dependence is more than twice as high in men than in women [25]. The diagnosis of antisocial personality disorder is more than three times as high in men than in women. On the other hand, severe mental disorders such as schizophrenia and bipolar disorder are associated with no pronounced gender differences in terms of the prevalence rate [25]. Among neurodevelopmental disorders, autism spectrum disorders (ASD) have consistent male predominance ranging from $2.5: 1$ to $4: 1$ in individuals with autistic disorder and $9: 1$ in individuals with Asperger disorder [26-28]. Attention deficit hyperactivity disorder (ADHD) is more commonly diagnosed in males than females, with male-to-female ratios ranging from $4: 1$ to $9: 1$ [29]. Eating disorders, which are one of the most important psychiatric categories of the behavioral aspects of PWS, are more common among females than males in both anorexia nervosa and bulimia nervosa [30, 31]. Equally important is the fact that the reverse pattern of gender disparity is found in "subthreshold binge eating disorder" $(0.6 \%$ women and $1.9 \%$ men) and that roughly comparable gender distribution is observed in the prevalence of "any binge eating" in women (4.9\%) and men (4.0\%) [32].

In terms of problems behavior in individuals with nonPWS mental retardation, findings regarding gender differences in Williams syndrome have been divided. Leyfer et al. [33], Pérez-García et al. [34], and Klein-Tasman et al. [35] did not find gender differences in psychiatric and problem behaviors. However, Porter et al. [36] found greater externalizing, somatic, affective, and conduct problems in girls. Also, Dykens [37] found that fearfulness was higher for girls than for boys. In the Down syndrome sample, problem behavior was more prevalent in boys than in girls [38]. By contrast, psychosis was predominantly seen in females with Down syndrome [39].

This study aims to explore gender differences in PWS in regard to the severity of behavioral symptoms. There are three inherent advantages in this study. Firstly, this is the only study of its kind in regard to gender differences in behavioral aspects of PWS, based on a large sample of the rare genetic disorder. Secondly, all subjects were recruited from a single institution and confirmed genetically with PWS using fluorescence in situ hybridization or the methylation test. Thirdly, all subjects with PWS were assessed by a single clinical psychologist (H.O.). Hence, the psychometrical data of this study can avoid the risk of interrater variability caused by participants being assessed by multiple assessors. At the same time, it should be noted that this single-center study has not only strength, but also weakness, because of sample selection bias and a small sample size.

\section{Subjects and Methods}

This study started upon receiving approval from the ethics committee of Dokkyo Medical University Koshigaya Hospital with which the authors were affiliated. After obtaining informed consent, the neurocognitive and behavioral assessment of each participant was carried out.

2.1. Subjects. Participants were 82 Japanese individuals with PWS recruited from a single location. The Department of Pediatrics, Dokkyo Medical University Koshigaya Hospital, was used for this purpose. All patients were diagnosed with PWS using fluorescence in situ hybridization or the methylation test. The participants consisted of 45 males (aged 6 to 58) and 37 females (aged 6 to 45), including 34 males and 25 females confirmed as having DEL involving 15q1113 and 11 males and 12 females confirmed as having mUPD of chromosome 15 (Table 1). Psychotropic medications were prescribed to 16 out of 45 males and 9 out of 37 females.

\subsection{Methods}

The Assessment of Behavior. An extended battery of behavioral assessment was employed. In all cases, the psychologist (H.O.) involved in collecting data was blind to the genetic status of each patient.

\subsection{Measures}

2.3.1. Intellectual Ability. To measure intellectual ability, a Japanese version of the Wechsler Intelligence Scale [40-43] was administered.

2.3.2. Food-Related Behaviors. To assess the severity of foodrelated behaviors, the Food Related Problem Questionnaire (FRPQ) was administered. This is an informant-based questionnaire to assess eating behaviors in people with PWS, consisting of 16 items, with three subscales (preoccupation with food (P), impairment of satiety (S), and other foodrelated negative behaviors $(\mathrm{N})$ ). Examples of the questions are as follows: "How often does the person compare the size or content of their meal with others?" (P); "After a normal sized meal, how often does the person say they still feel hungry?" (S); and "If given the opportunity, how often would the person "help themselves" to food which they should not have?" (N). As Russell and Oliver [44] presented, the FRPQ has sufficiently robust psychometric properties to appraise the food-related problems in individuals with PWS. 
TABLE 1: Patient characteristics.

\begin{tabular}{lcccccc}
\hline & Total & Male & Female & DEL & mUPD & \multicolumn{2}{c}{$p$ value $(t$-test) } \\
Genotype groups
\end{tabular}

${ }^{*} p<0.05$.

2.3.3. Aberrant Behaviors. To assess the degree of problem behaviors in individuals with PWS, the Aberrant Behavior Checklist Japanese Version (ABC-J) [45] was applied. It is a 58-item checklist which takes about 10-15 minutes to complete. There are five subscales: (a) irritability and agitation, (b) lethargy and social withdrawal, (c) stereotypic behavior, (d) hyperactivity and noncompliance, and (e) inappropriate speech. It was found that the ABC identifies salient features of mental illness in individuals with mental retardation [46], including autism spectrum disorder [47], and is an effective tool in measuring treatment response $[46,48]$.

2.3.4. Routine Behaviors. To measure the extent of routines, the Childhood Routines Inventory (CRI) was administered. This is a parent-report checklist of commonly occurring children's routines [49], consisting of 19 items, including 5 items for "just right behavior" and 5 items for "repetitive behavior." An example of the former is "Prefers to have things done in a particular order" and that of the latter is "Prefers the same household schedules or routines." It was found that the CRI is an effective tool in measuring the severity of routine behaviors in normal young children [49] and children with Down syndrome [50].

2.3.5. Autistic Symptomatology. Autistic symptomatology was assessed using the Pervasive Developmental Disorders Autism Society Japan Rating Scale (PARS) [51, 52]. This scale is a behavior checklist, developed as a screening questionnaire to determine pervasive developmental disorders (PDDs). When assessing adolescents and adults, 33 items for adolescents, partially shared by those for children, are applied for the evaluation of current autistic states. The PARS for adolescents is made up to five clinical subscores consisting of interpersonal skills (6 items), communication (7 items), obsession (6 items), problematic behaviors (11 items), and hypersensitivity (3 items).

2.3.6. Inattention and Hyperactivity/Impulsivity. The Japanese ADHD-RS [53] was administered to all participants. The ADHD-RS [54] obtains parent ratings regarding the frequency of each ADHD symptom based on DSM-IV criteria. The scale consists of 2 subscales: inattention ( 9 items) and hyperactivity/impulsivity (9 items). Parents are asked to state the degree to which they best describe the child's behavior over the previous 6 months. All items are scored on a 4-point Likert scale from 0 ("rarely or never") to 3 ("always or very often"), with higher scores reflecting higher degree of inattention and hyperactivity/impulsivity. The reliability and the validity of the Japanese ADHD-RS have already been established [53].

By means of a numerical coding system, all data were guarded under strict confidentiality and anonymity. The data were analyzed by SPSS 20.0J for Windows. The results are expressed as mean (SD and range). To examine the effect that gender and genotype have on the severity of behavioral symptoms, two-way analyses of variance (ANOVAs) were conducted. The two gender groups (male versus female) and the two genotypes of PWS (DEL and mUPD) were used as independent variables, and the behavioral scores were used as dependent variables.

\section{Results}

As Table 1 shows, the mean IQs in both males and females were slightly less than 50, with no statistical difference between both groups. These scores are more than 50 points under the normative population score of 100, indicating a considerable impairment in intellectual abilities. As far as genotypes are concerned, a statistically significant difference was found between DEL and MUPD, with higher scores in the DEL group $[15,55]$.

Table 2 shows the results in regard to the degree of behavioral symptoms of PWS individuals. In order to examine the effects that genders and genotypes have on the symptom's severity, two-way ANOVAs were conducted. The two gender groups and the two genotypes of PWS were used as independent variables, and the scores of the FRPQ, the ABC-J, the CRI, the PARS, and the ADHD-RS were used as dependent variables.

Statistically significant interactions between genders and genotypes were found only in regard to FRPQ scores: FRPQ total score $(F(1,78)=8.43, p<0.01)$, FRPQ-P $(F(1,78)=$ 6.66, $p<0.05)$, FRPQ-S $(F(1,78)=7.74, p<0.01)$, and FRPQ-N $(F(1,78)=4.04, p<0.05)$. On finding this, a Bonferroni procedure was performed to test the simple main effects.

In terms of the FRPQ total score, it was found that the score of male DEL was higher than that of female DEL $(F(1,78)=4.22, p<0.05)$; on the contrary, the score of male $\operatorname{mUPD}$ was lower than that of female $\operatorname{mUPD}(F(1,78)=4.56$, $p<0.05)$. Besides, the FRPQ score of male DEL was found 
TABLE 2: The FRPQ, ABCJ, CRI, PARS, and ADHD-RS scores and the results of two-way ANOVA using the two gender groups and the two genotypes.

\begin{tabular}{|c|c|c|c|c|c|c|c|}
\hline & Total & & & $\mathrm{Ge}$ & ype & ANOI & eraction \\
\hline & 10 tal & Male & Female & DEL & mUPD & $F$ & $p$ \\
\hline FRPQ total & $34.4 \pm 15.0$ & $35.6 \pm 15.3$ & $33.0 \pm 14.8$ & $37.3 \pm 14.6$ & $27.0 \pm 13.6$ & 8.43 & $0.005^{*}$ \\
\hline FRPQ-P & $9.3 \pm 4.4$ & $9.5 \pm 4.5$ & $9.0 \pm 4.3$ & $9.8 \pm 4.4$ & $8.0 \pm 4.2$ & 6.66 & $0.012^{*}$ \\
\hline FRPQ-S & $15.4 \pm 6.3$ & $16.0 \pm 6.1$ & $14.8 \pm 6.5$ & $16.3 \pm 6.1$ & $13.3 \pm 6.3$ & 7.74 & $0.007^{*}$ \\
\hline FRPQ-N & $9.7 \pm 6.9$ & $10.1 \pm 7.1$ & $9.2 \pm 6.7$ & $11.3 \pm 6.8$ & $5.7 \pm 5.3$ & 4.04 & $0.048^{*}$ \\
\hline $\mathrm{ABCJ}$ total & $33.2 \pm 29.4$ & $34.3 \pm 30.8$ & $31.8 \pm 27.9$ & $30.7 \pm 27.0$ & $39.8 \pm 35.2$ & 0.91 & 0.344 \\
\hline ABCJ excitement & $11.3 \pm 10.2$ & $12.0 \pm 10.2$ & $10.4 \pm 10.2$ & $11.2 \pm 10.1$ & $11.6 \pm 0.6$ & 1.20 & 0.277 \\
\hline ABCJ apathy & $7.1 \pm 8.0$ & $6.6 \pm 7.3$ & $7.7 \pm 8.9$ & $5.8 \pm 6.3$ & $10.6 \pm 10.7$ & 2.16 & 0.145 \\
\hline ABCJ stereotype & $2.1 \pm 3.2$ & $1.9 \pm 2.9$ & $2.3 \pm 3.6$ & $1.7 \pm 2.7$ & $3.2 \pm 4.2$ & 0.93 & 0.337 \\
\hline ABCJ hyperactivity & $8.6 \pm 9.2$ & $9.5 \pm 10.6$ & $7.4 \pm 7.1$ & $8.1 \pm 8.7$ & $9.9 \pm 10.7$ & 0.06 & 0.812 \\
\hline $\mathrm{ABCJ}$ inappropriate & $4.0 \pm 3.2$ & $4.2 \pm 3.2$ & $3.8 \pm 3.3$ & $4.0 \pm 3.3$ & $4.2 \pm 3.0$ & 0.27 & 0.603 \\
\hline CRI total & $3.1 \pm 1.6$ & $2.8 \pm 1.5$ & $3.3 \pm 1.8$ & $3.1 \pm 1.7$ & $2.9 \pm 1.6$ & 0.38 & 0.542 \\
\hline CRI Fre & $9.3 \pm 5.8$ & $8.0 \pm 5.1$ & $10.7 \pm 6.2$ & $9.7 \pm 5.8$ & $8.5 \pm 5.8$ & 0.84 & 0.364 \\
\hline CRI Jr & $0.8 \pm 0.8$ & $0.8 \pm 0.9$ & $0.7 \pm 0.8$ & $0.9 \pm 0.7$ & $0.5 \pm 1.0$ & 0.85 & 0.363 \\
\hline CRI JrFre & $2.1 \pm 2.6$ & $2.2 \pm 2.8$ & $2.1 \pm 2.5$ & $2.3 \pm 2.0$ & $1.7 \pm 3.6$ & 0.51 & 0.480 \\
\hline CRI Re & $0.7 \pm 0.6$ & $0.6 \pm 0.6$ & $0.8 \pm 0.7$ & $0.7 \pm 0.7$ & $0.8 \pm 0.6$ & 0.16 & 0.687 \\
\hline CRI ReFre & $2.1 \pm 2.1$ & $1.5 \pm 1.5$ & $2.7 \pm 2.5$ & $2.1 \pm 2.3$ & $2.2 \pm 1.8$ & 0.03 & 0.868 \\
\hline PARS child & $9.8 \pm 7.0$ & $10.2 \pm 7.7$ & $9.2 \pm 5.5$ & $9.4 \pm 6.6$ & $11.3 \pm 8.0$ & 0.00 & 0.972 \\
\hline PARS adolescent and adult & $17.0 \pm 9.2$ & $16.9 \pm 9.4$ & $17.2 \pm 9.2$ & $15.9 \pm 9.1$ & $21.6 \pm 8.8$ & 1.06 & 0.307 \\
\hline ADHD-RS total & $4.9 \pm 5.9$ & $5.3 \pm 6.7$ & $4.1 \pm 3.8$ & $4.6 \pm 5.7$ & $5.7 \pm 6.6$ & 0.02 & 0.902 \\
\hline ADHD-RS inattention & $2.9 \pm 3.4$ & $3.1 \pm 3.8$ & $2.5 \pm 2.3$ & $2.7 \pm 3.0$ & $3.5 \pm 4.3$ & 0.02 & 0.877 \\
\hline ADHD-RS hyperactivity/impulsivity & $2.0 \pm 3.1$ & $2.2 \pm 3.5$ & $1.5 \pm 2.2$ & $1.9 \pm 3.3$ & $2.3 \pm 2.5$ & 0.16 & 0.687 \\
\hline
\end{tabular}

${ }^{*} p<0.05$.

FRPQ: Food Related Problem Questionnaire; FRPQ-P: preoccupation with food, S: impairment of satiety, N: composite negative behavior; ABC-J: Aberrant Behavior Checklist-Community Japan Rating Scale; CRI: Childhood Routine Inventory; CRI Jr: just right behaviors, Re: repetitive behaviors, Fre: frequency/intensity score; PARS: Pervasive Developmental Disorders Autism Society Japan Rating Scale; ADHD-RS: ADHD Rating Scale.

to be higher than that of male $\operatorname{mUPD}(F(1,78)=17.43$, $p<0.01)$.

In regard to the FRPQ subscores, the FRPQ-P (preoccupation) score of male DEL was higher than that of male $\operatorname{mUPD}(F(1,78)=8.79, p<0.01)$. The FRPQ-S (satiety) score of male DEL was higher than that of female DEL $(F(1,78)=4.43, p<0.05)$ and was higher than that of male $\operatorname{mUPD}(F(1,78)=11.32, p<0.01)$. The FRPQ-N (negativity) score of male DEL was higher than that of male $\operatorname{mUPD}(F(1,78)=15.84, p<0.01)$ (Figure 1).

\section{Discussion}

To our knowledge, this study is the first attempt to compare a wide range of behavioral features of PWS between male and female groups. To examine the effect that genotypes as well as genders have on the severity of behavioral symptoms, two-way analyses of variance (ANOVAs) were conducted. Two gender groups and two genotypes of PWS were used as independent variables. Apart from food-related behaviors, no significant statistical differences were found between male and female in regard to other behavioral features, such as problem behaviors, routines, autistic symptoms, inattention, and hyperactivity. As a whole, male and female PWS patients seem to be more similar than different regarding PWSrelated behavioral symptoms. In this respect, our data accord with previous reports, which found similarities, rather than differences, in behavior between male and female [56-58].

The two-way ANOVAs to examine the interaction between gender and genotype, followed by the Bonferroni procedure to test the simple main effects, showed the following: food-related behaviors of male DEL were more severe than those of female DEL, and on the contrary food-related behaviors of male mUPD were less severe than those of female mUPD. Thus, the reverse pattern of gender disparity between the two genotypes was found.

These data contradicted the recent report of Jauregi et al. [58], who found female dominant scores in only two among the twenty-two items of the Developmental Behavior Checklist for Adults: "irritability" and "distress over small changes in their routine or environment." Aside from these items, they did not find significant differences between male and female behaviors. At the same time, they found significant differences between DEL and non-DEL, such as "increase in appetite" with a higher score in DEL. Indeed, Dykens et al. [59] showed the lack of significant relations between food-related behaviors and genetic status. However, as the results suggest, the relationship between hyperphagia 

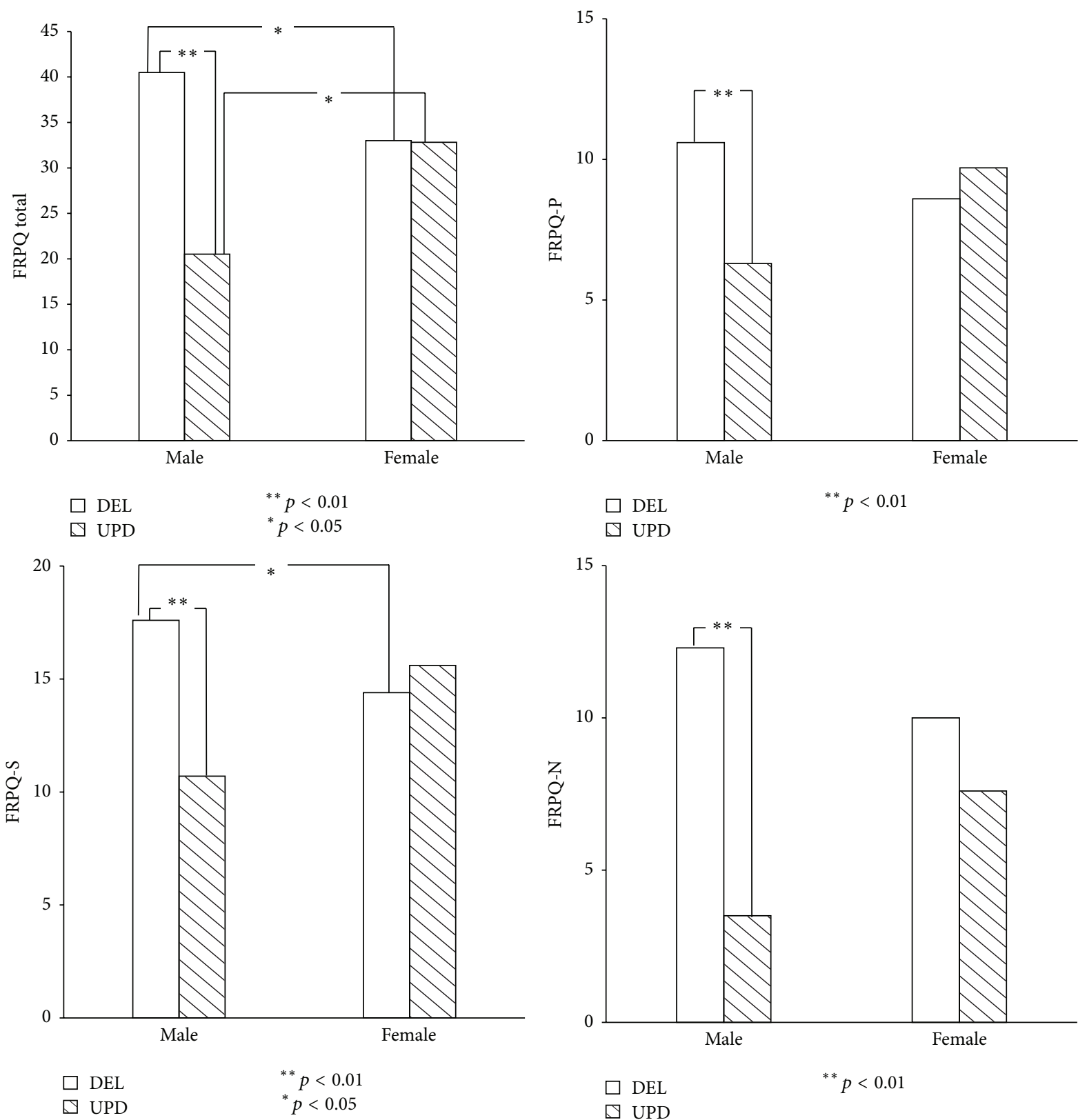

FIGURE 1: The effect of gender (male versus female) and genotype (DEL versus UPD) of PWS on the total score and preoccupation (P), impairment of satiety $(\mathrm{S})$, and composite negative behavior $(\mathrm{N})$ domains of FRPQ.

and genotype may be complicated by gender disparity. There seems to be a need for further investigation in terms of the impact of the gender differences on the relationship between genetic status, hyperphagia, and other behavioral symptoms.

It is evident that further methodological limitations exist in this study. First, the impact of biological changes in chronological adolescence was not considered. Unfortunately, the number of patients enrolled in this study was too small to analyze gender differences in the behavioral data in multiple age groups. According to Ogata et al. [15], there is a growing tendency for the autistic and impulsive behavioral problems, which are more severe in mUPD than in DEL that can manifest themselves later in adolescence. Likewise, gender differences in the behavioral symptom severity should take age, as well as genotypes, into consideration.

Second, this study did not encompass the entire range of psychiatric disorders relevant to gender differences in PWS. For example, it remains to be seen in regard to clinical categories whose rate is known to show striking gender differences. They include male-dominant disorders, such as alcohol dependence and antisocial personality disorder, and female-dominant ones, such as depression, anxiety, and somatic complaints [25]. Moreover, this study did not cover affective and psychotic disorders, in spite of the fact that 
the PWS group was known to have higher rates of affective disorders with psychotic features [60]. Although little is known about gender differences, PWS individuals with a psychotic disorder showed a disproportionate number of mUPD patients [61]. A more comprehensive study is required to illuminate gender differences in the severity of various psychiatric categories in PWS.

Third, a future study should assess the influence of endocrinological factors including growth hormone therapy and diabetes on the behavioral aspects with PWS focusing on gender differences. Based on 35 Brazilian patients with PWS, Quaio et al. [62] demonstrated that growth hormone treatment considerably improved the control of weight gain and body mass index for female patients but no effect on either parameter in male patients. They suggested that in male patients the benefits of growth hormone treatment may have been overcome by other factors, such as food-intake behaviors. The relationship between the gender differences in the effects of growth hormone treatment and those in food-related behaviors is an area worthy of further exploration, because it could potentially throw a new light on the possibility of gender-specific hormonal treatment to PWS. Aside from food-related behaviors, another gender-specific hormonal treatment was conducted by Kido et al. [63]. They found that testosterone replacement therapy improved secondary sexual characteristics and body composition without adverse behavioral problems in male patients with PWS. Finally, due to a single-institution study that aimed at a rare genetic disorder, the size of sample is relatively small. For this reason, the male-female similarity regarding PWSrelated behaviors in this study should be interpreted with caution.

\section{Conflict of Interests}

Kazutaka Shimoda has received research support from Shionogi \& Co. Ltd., Eli Lilly Japan K.K., Yoshitomi Pharmaceutical Industries Ltd., Meiji Seika Pharma Co. Ltd., Eisai Co. Ltd., Pfizer Inc., GlaxoSmithKline K.K., Otsuka Pharmaceutical Co. Ltd., Daiichi Sankyo Co., and Takeda Pharmaceutical Co. Ltd. and honoraria from Kowa Pharmaceutical Co. Ltd., Mitsubishi Tanabe Pharma Corporation, Meiji Seika Pharma Co. Ltd., Dainippon Sumitomo Pharma Co. Ltd., Ono Pharmaceutical Co. Ltd., GlaxoSmithKline K.K., and Eisai Co. Ltd. All other authors declare no biomedical or financial interests or potential conflict of interests directly relevant to the content of the present study.

\section{Authors' Contribution}

Masao Gito and Hiroshi Ihara managed this work and were equal contributors in writing the paper. Hiroyuki Ogata conducted the assessments. Masayuki Sayama drafted the figure. Nobuyuki Murakami, Toshiro Nagai, Tadayuki Ayabe, and Yuji Oto collected the samples. Toshiro Nagai is the leader of the PWS research project and Kazutaka Shimoda is the coordinator at department of psychiatry, Dokkyo Medical University School of Medicine.

\section{Acknowledgment}

This research was supported by a grant for the Research Support Foundation from the Juntendo Institute of Psychiatry in the fiscal year 2015 (Heisei 27).

\section{References}

[1] S. B. Cassidy and D. J. Driscoll, "Prader-Willi syndrome," European Journal of Human Genetics, vol. 17, no. 1, pp. 3-13, 2009.

[2] A. Crinò, R. Schiaffini, P. Ciampalini et al., "Hypogonadism and pubertal development in Prader-Willi syndrome," European Journal of Pediatrics, vol. 162, no. 5, pp. 327-333, 2003.

[3] J. E. Whittington, A. J. Holland, T. Webb, J. Butler, D. Clarke, and H. Boer, "Population prevalence and estimated birth incidence and mortality rate for people with Prader-Willi syndrome in one UK Health Region," Journal of Medical Genetics, vol. 38, no. 11, pp. 792-798, 2001.

[4] A. J. Holland, J. Treasure, P. Coskeran, J. Dallow, N. Milton, and E. Hillhouse, "Measurement of excessive appetite and metabolic changes in Prader-Willi syndrome," International Journal of Obesity, vol. 17, no. 9, pp. 527-532, 1993.

[5] C. J. McAllister, J. E. Whittington, and A. J. Holland, "Development of the eating behaviour in Prader-Willi Syndrome: advances in our understanding," International Journal of Obesity, vol. 35, no. 2, pp. 188-197, 2011.

[6] P. Tunnicliffe, K. Woodcock, L. Bull, C. Oliver, and J. Penhallow, "Temper outbursts in Prader-Willi syndrome: causes, behavioural and emotional sequence and responses by carers," Journal of Intellectual Disability Research, vol. 58, no. 2, pp. 134150, 2014.

[7] E. M. Dykens, J. F. Leckman, and S. B. Cassidy, "Obsessions and compulsions in Prader-Willi syndrome," Journal of Child Psychology and Psychiatry and Allied Disciplines, vol. 37, no. 8, pp. 995-1002, 1996.

[8] M. J. Descheemaeker, A. Vogels, V. Govers et al., "PraderWilli syndrome: new insights in the behavioural and psychiatric spectrum," Journal of Intellectual Disability Research, vol. 46, no. 1, pp. 41-50, 2002.

[9] N. Greaves, E. Prince, D. W. Evans, and T. Charman, "Repetitive and ritualistic behaviour in children with Prader-Willi syndrome and children with autism," Journal of Intellectual Disability Research, vol. 50, part 2, pp. 92-100, 2006.

[10] K. Arron, C. Oliver, J. Moss, K. Berg, and C. Burbidge, “The prevalence and phenomenology of self-injurious and aggressive behaviour in genetic syndromes," Journal of Intellectual Disability Research, vol. 55, no. 2, pp. 109-120, 2011.

[11] M. Klabunde, M. Saggar, K. M. Hustyi, J. L. Hammond, A. L. Reiss, and S. S. Hall, "Neural correlates of self-injurious behavior in Prader-Willi syndrome," Human Brain Mapping, vol. 36, no. 10, pp. 4135-4143, 2015.

[12] M.-J. Descheemaeker, V. Govers, P. Vermeulen, and J.-P. Fryns, "Pervasive developmental disorders in Prader-Willi syndrome: the Leuven experience in 59 subjects and controls," American Journal of Medical Genetics Part A, vol. 140, no. 11, pp. 1136-1142, 2006.

[13] E. M. Dykens, E. Lee, and E. Roof, "Prader-Willi syndrome and autism spectrum disorders: an evolving story," Journal of Neurodevelopmental Disorders, vol. 3, no. 3, pp. 225-237, 2011. 
[14] M. Wigren and S. Hansen, "ADHD symptoms and insistence on sameness in Prader-Willi syndrome," Journal of Intellectual Disability Research, vol. 49, no. 6, pp. 449-456, 2005.

[15] H. Ogata, H. Ihara, N. Murakami, M. Gito, Y. Kido, and T. Nagai, "Autism spectrum disorders and hyperactive/impulsive behaviors in Japanese patients with Prader-Willi syndrome: a comparison between maternal uniparental disomy and deletion cases," American Journal of Medical Genetics Part A, vol. 164, no. 9, pp. 2180-2186, 2014.

[16] E. Dykens and B. Shah, "Psychiatric disorders in Prader-Willi syndrome: epidemiology and management," CNS Drugs, vol. 17, no. 3, pp. 167-178, 2003.

[17] A. Y. Ho and A. Dimitropoulos, "Clinical management of behavioral characteristics of Prader-Willi syndrome," Neuropsychiatric Disease and Treatment, vol. 6, pp. 107-118, 2010.

[18] M. G. Butler, "Prader-Willi syndrome: current understanding of cause and diagnosis," American Journal of Medical Genetics, vol. 35, no. 3, pp. 319-332, 1990.

[19] A. Akefeldt, C. Gillberg, and C. Larsson, "Prader-Willi syndrome in a Swedish rural county: epidemiological aspects," Developmental Medicine and Child Neurology, vol. 33, no. 8, pp. 715-721, 1991.

[20] G. Grugni, A. Crinò, L. Bosio et al., "The Italian National survey for Prader-Willi syndrome: an epidemiologic study," American Journal of Medical Genetics Part A, vol. 146, no. 7, pp. 861-872, 2008.

[21] H. Ehara, K. Ohno, and K. Takeshita, "Frequency of the Prader-Willi syndrome in the San-in district, Japan," Brain \& Development, vol. 17, no. 5, pp. 324-326, 1995.

[22] E. M. Dykens, "Maladaptive and compulsive behavior in Prader-Willi syndrome: new insights from older adults," American Journal on Mental Retardation, vol. 109, no. 2, pp. 142-195, 2004.

[23] E. M. Dykens and C. Kasari, "Maladaptive behavior in children with Prader-Willi syndrome, Down syndrome, and nonspecific mental retardation," American Journal on Mental Retardation, vol. 102, no. 3, pp. 228-237, 1997.

[24] J. Mitchell, A. Schinzel, S. Langlois et al., "Comparison of phenotype in uniparental disomy and deletion Prader-Willi syndrome: sex specific differences," American Journal of Medical Genetics, vol. 65, no. 2, pp. 133-136, 1996.

[25] World Health Organization, Gender and Women's Mental Health, WHO Press, Geneva, Switzerland, 2007.

[26] E. Fombonne, "Epidemiological surveys of autism and other pervasive developmental disorders: an update," Journal of Autism and Developmental Disorders, vol. 33, no. 4, pp. 365-382, 2003.

[27] Centers for Disease Control and Prevention, "Prevalence of autism spectrum disorders-autism and developmental disabilities monitoring network, 14 sites, United States, 2008," Morbidity and Mortality Weekly Report, vol. 61, no. 3, pp. 1-19, 2012.

[28] Y. S. Kim, B. L. Lventhal, Y. J. Koh et al., "Prevalence of autism spectrum disorders in a total population sample," The American Journal of Psychiatry, vol. 168, no. 9, pp. 904-912, 2011.

[29] American Psychological Association, Attention-Deficit/Hyperactivity Disorder: Abstracts of the Psychological and Behavioral Literature, 1971-1994, vol. 14 of Bibliographies in Psychology, American Psychological Association, 1994.

[30] H. W. Hoek, "Incidence, prevalence and mortality of anorexia nervosa and other eating disorders," Current Opinion in Psychiatry, vol. 19, no. 4, pp. 389-394, 2006.
[31] R. H. Striegel-Moore and C. M. Bulik, "Risk factors for eating disorders," The American Psychologist, vol. 62, no. 3, pp. 181-198, 2007.

[32] J. I. Hudson, E. Hiripi, H. G. Pope Jr., and R. C. Kessler, "The prevalence and correlates of eating disorders in the National Comorbidity Survey Replication," Biological Psychiatry, vol. 61, no. 3, pp. 348-358, 2007.

[33] O. T. Leyfer, J. Woodruff-Borden, B. P. Klein-Tasman, J. S. Fricke, and C. B. Mervis, "Prevalence of psychiatric disorders in 4 to 16-year-olds with Williams syndrome," American Journal of Medical Genetics Part B: Neuropsychiatric Genetics, vol. 141, no. 6, pp. 615-622, 2006.

[34] D. Pérez-García, R. Granero, F. Gallastegui, L. A. Pérez-Jurado, and C. Brun-Gasca, "Behavioral features of Williams Beuren syndrome compared to Fragile X syndrome and subjects with intellectual disability without defined etiology," Research in Developmental Disabilities, vol. 32, no. 2, pp. 643-652, 2011.

[35] B. P. Klein-Tasman, E. N. Lira, K. T. Li-Barber, F. J. Gallo, and N. G. Brei, "Parent and teacher perspectives about problem behavior in children with Williams syndrome," American Journal on Intellectual and Developmental Disabilities, vol. 120, no. 1, pp. 72-86, 2015.

[36] M. A. Porter, H. Dodd, and D. Cairns, "Psychopathological and behavior impairments in Williams-Beuren syndrome: the influence of gender, chronological age, and cognition," Child Neuropsychology, vol. 15, no. 4, pp. 359-374, 2009.

[37] E. M. Dykens, "Anxiety, fears, and phobias in persons with Williams syndrome," Developmental Neuropsychology, vol. 23, no. 1-2, pp. 291-316, 2003.

[38] H. B. M. van Gameren-Oosterom, M. Fekkes, J. P. van Wouwe, S. B. Detmar, A. M. Oudesluys-Murphy, and P. H. Verkerk, "Problem behavior of individuals with down syndrome in a nationwide cohort assessed in late adolescence," Journal of Pediatrics, vol. 163, no. 5, pp. 1396-1401, 2013.

[39] E. M. Dykens, B. Shah, B. Davis, C. Baker, T. Fife, and J. Fitzpatrick, "Psychiatric disorders in adolescents and young adults with Down syndrome and other intellectual disabilities," Journal of Neurodevelopmental Disorders, vol. 7, article 9, 2015.

[40] D. Wechsler, Wechsler Intelligence Scale for Children, The Psychological Corporation, San Antonio, Tex, USA, 3rd edition, 1991.

[41] Japanese WISC-III Publication Committee, Japanese Wechslar Intelligence Scale for Children, Nihon Bunka Kagakusya, 3rd edition, 1998.

[42] D. Wechsler, Wechsler Adult Intelligence Scale, The Psychological Corporation, San Antonio, Tex, USA, 3rd edition, 1997.

[43] Japanese WAIS-III Publication Committee, Japanese Wechsler Adult Intelligemce Scale, Nihon Bunka Kagakusya, 3rd edition, 2006.

[44] H. Russell and C. Oliver, "The assessment of food-related problems in individuals with Prader-Willi syndrome," British Journal of Clinical Psychology, vol. 42, no. 4, pp. 379-392, 2003.

[45] G. M. Aman, N. N. Singh, and Y. Ono, Clinical Evaluation of Aberrant Behavior Checklist Japanese Version (ABC-J), Jiho, Tokyo, Japan, 2006.

[46] K. J. Shedlack, J. Hennen, C. Magee, and D. M. Cheron, "A comparison of the Aberrant Behavior Checklist and the GAF among adults with mental retardation and mental illness," Psychiatric Services, vol. 56, no. 4, pp. 484-486, 2005.

[47] J. Brinkley, L. Nations, R. K. Abramson et al., "Factor analysis of the aberrant behavior checklist in individuals with autism 
spectrum disorders," Journal of Autism and Developmental Disorders, vol. 37, no. 10, pp. 1949-1959, 2007.

[48] S. R. Schroeder, J. Rojahn, and R. M. Reese, "Reliability and validity of instruments for assessing psychotropic medication effects on self-injurious behavior in mental retardation," Journal of Autism and Developmental Disorders, vol. 27, no. 1, pp. 89-102, 1997.

[49] D. W. Evans, J. F. Leckman, A. Carter et al., "Ritual, habit and perfectionism: the prevalence and development of compulsivelike behaviour in normal young children," Child Development, vol. 68, no. 1, pp. 58-68, 1997.

[50] D. W. Evans and F. L. Gray, "Compulsive-like behavior in individuals with down syndrome: its relation to mental age level, adaptive and maladaptive behavior," Child Development, vol. 71, no. 2, pp. 288-300, 2000.

[51] J. Adachi, R. Yukihiro, M. Inoue, T. Uchiyama, Y. Kamio, and H. Kurita, "Reliability and validity of the childhood part of the PARS (PDD-Autism Society Japan Rating Scale)," Rinsyoseishinigaku, vol. 35, pp. 1591-1599, 2006 (Japanese).

[52] Y. Kamio, R. Yukihiro, J. Adachi et al., "Reliability and Validity of the Pervasive Developmental Disorder(PDD)-Autism Society Japan Rating Scale(PARS): a behavior checklist for adolescents and adults with PDDs," Seishinigaku, vol. 48, pp. 495-505, 2006 (Japanese).

[53] H. Ichikawa and Y. Tanaka, ADHD-Rating Scale-IV: Checklists, Norms, and Clinical Interpretation, Akashi Shoten, 2008 (Japanese).

[54] J. DuPaul, J. Power, D. Anastopoulos, and R. Reid, ADHDRating Scale-IV: Checklists, Norms, and Clinical Interpretation, Guilford Press, 1998.

[55] S.-G. Shu, S. Chien, Y.-C. Wu, P.-L. Tsai, and J.-K. Yih, "Anthropometric and intellectual evaluation of individuals with PraderWilli syndrome," Journal of the Formosan Medical Association, vol. 106, no. 6, pp. 509-512, 2007.

[56] M. Sinnema, S. L. Einfeld, C. T. R. M. Schrander-Stumpel, M. A. Maaskant, H. Boer, and L. M. G. Curfs, "Behavioral phenotype in adults with Prader-Willi syndrome," Research in Developmental Disabilities, vol. 32, no. 2, pp. 604-612, 2011.

[57] H.-C. Steinhausen, U. Eiholzer, B. P. Hauffa, and Z. Malin, "Behavioural and emotional disturbances in people with Prader-Willi syndrome," Journal of Intellectual Disability Research, vol. 48, no. 1, pp. 47-52, 2004.

[58] J. Jauregi, V. Laurier, P. Copet, M. Tauber, and D. Thuilleaux, "Behavioral profile of adults with Prader-Willi syndrome: correlations with individual and environmental variables," Journal of Neurodevelopmental Disorders, vol. 5, no. 1, article 18, 2013.

[59] E. M. Dykens, M. A. Maxwell, E. Pantino, R. Kossler, and E. Roof, "Assessment of hyperphagia in prader-Willi syndrome," Obesity, vol. 15, no. 7, pp. 1816-1826, 2007.

[60] A. Beardsmore, T. Dorman, S.-A. Cooper, and T. Webb, "Affective psychosis and Prader-Willi syndrome," Journal of Intellectual Disability Research, vol. 42, no. 6, pp. 463-471, 1998.

[61] W. M. Verhoeven, S. Tuinier, and L. M. Curfs, "Prader-Willi syndrome: the psychopathological phenotype in uniparental disomy," Journal of Medical Genetics, vol. 40, article e112, 2003.

[62] C. R. Quaio, T. F. Almeida, L. M. J. Albano et al., "A clinical follow-up of 35 Brazilian patients with Prader-Willi syndrome," Clinics, vol. 67, no. 8, pp. 917-921, 2012.

[63] Y. Kido, S. Sakazume, Y. Abe et al., “Testosterone replacement therapy to improve secondary sexual characteristics and body composition without adverse behavioral problems in adult male patients with Prader-Willi syndrome: an observational study," American Journal of Medical Genetics A, vol. 161, no. 9, pp. 21672173, 2013. 


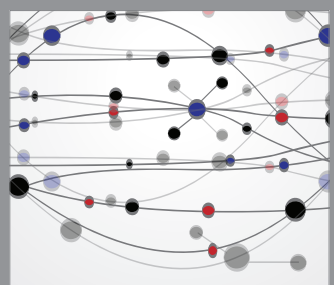

The Scientific World Journal
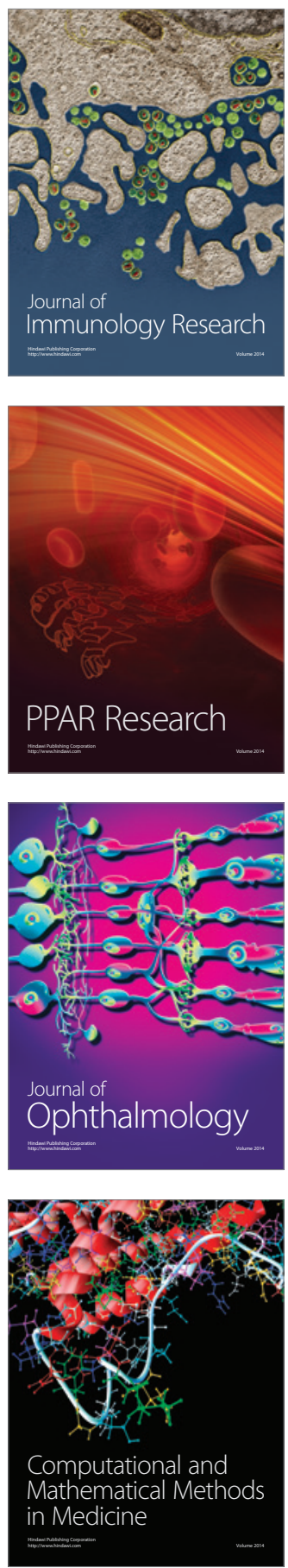

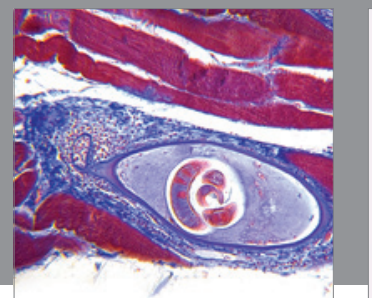

Gastroenterology

Research and Practice
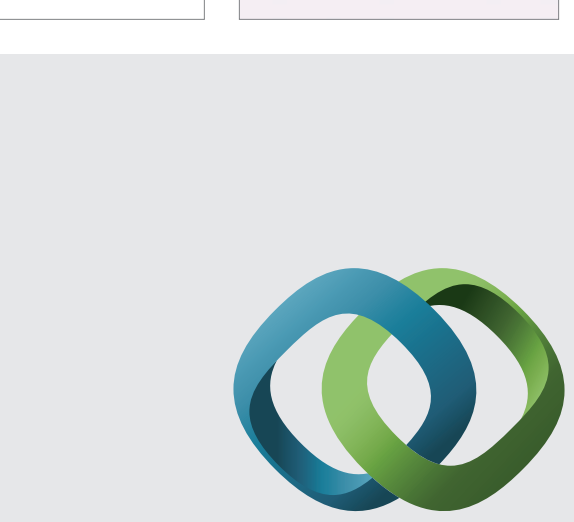

\section{Hindawi}

Submit your manuscripts at

http://www.hindawi.com
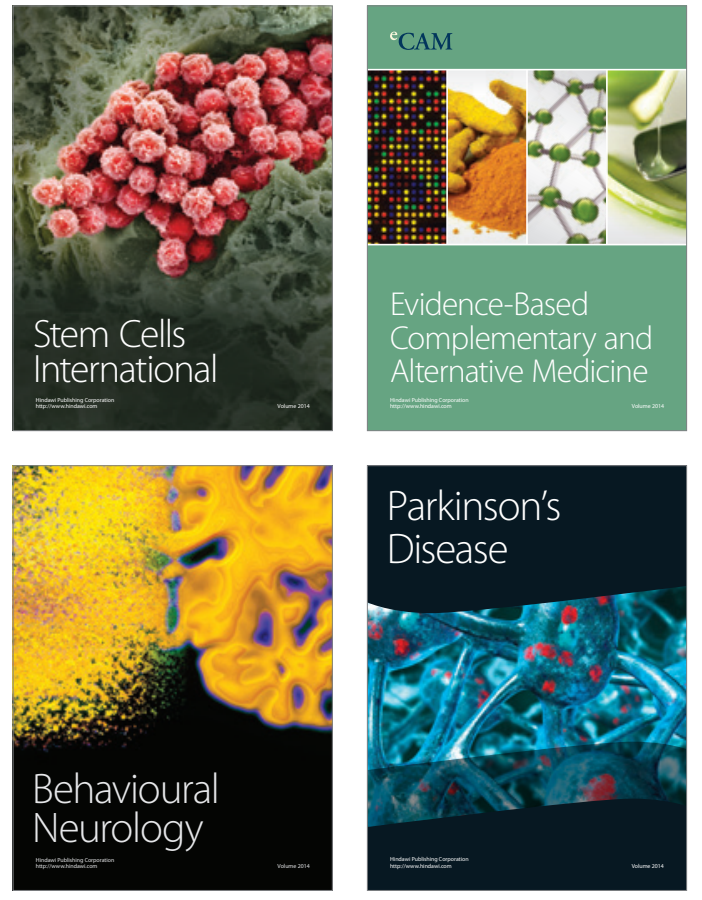
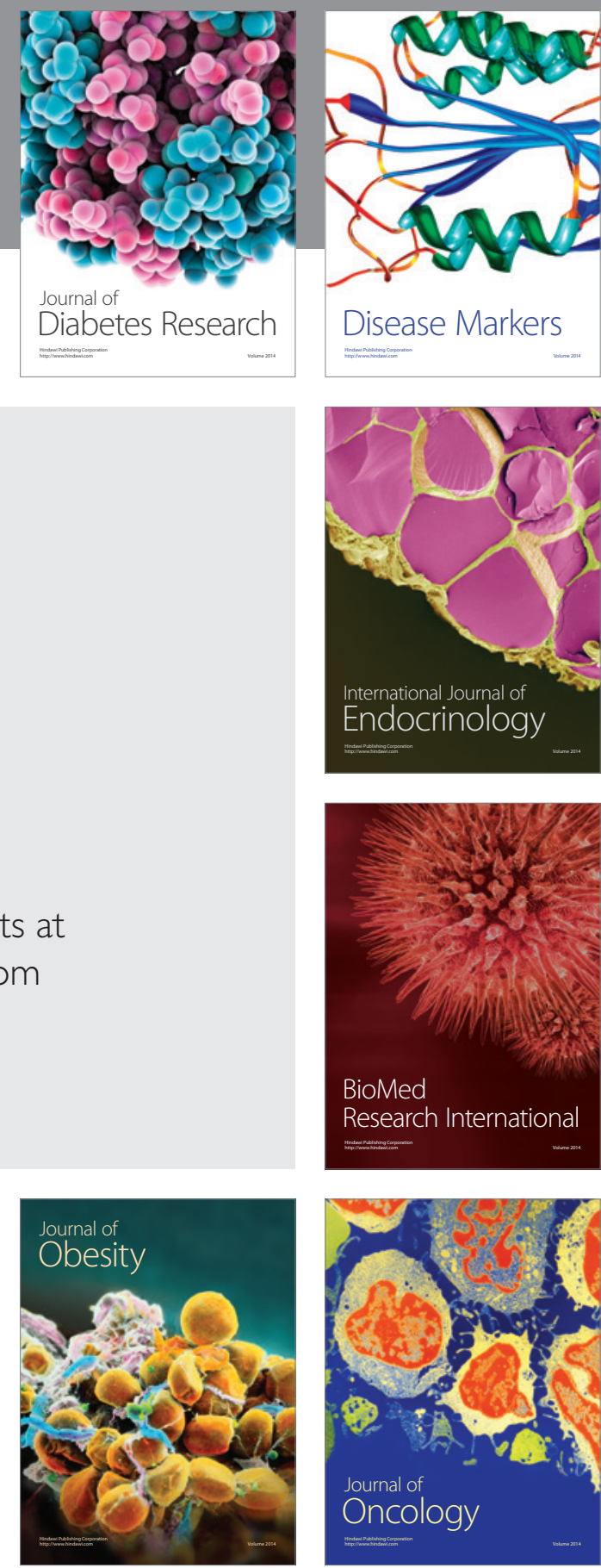

Disease Markers
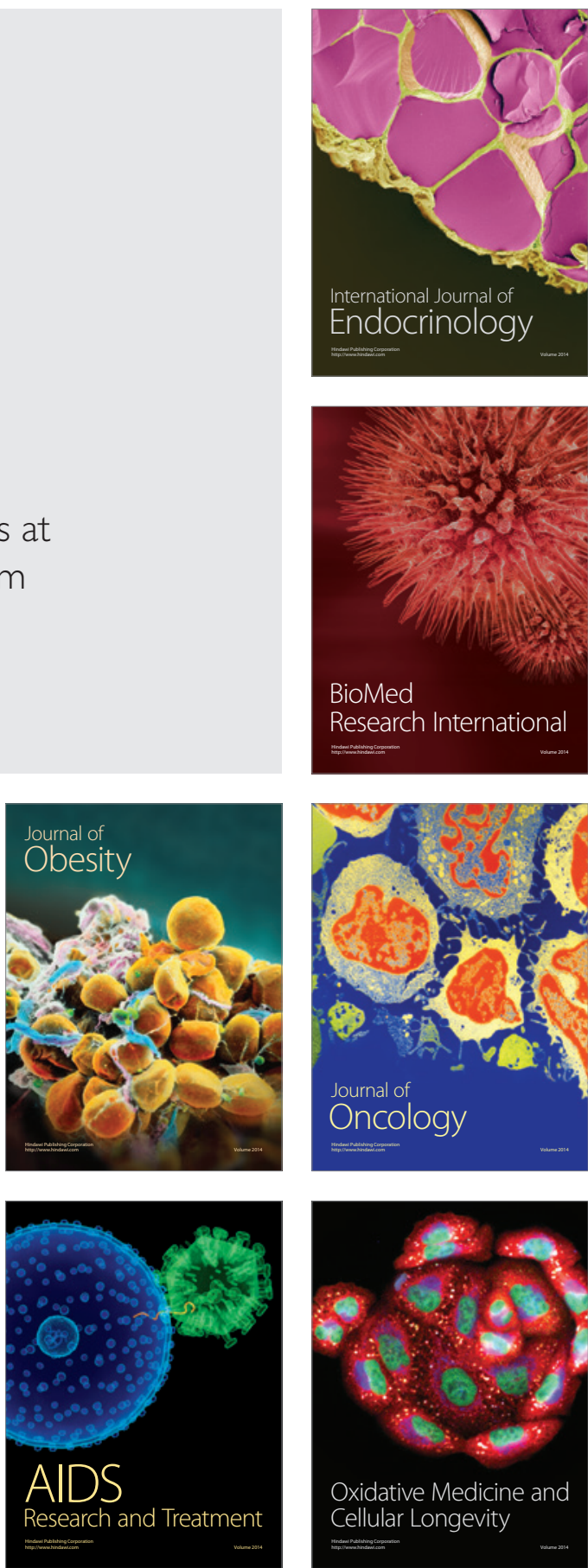